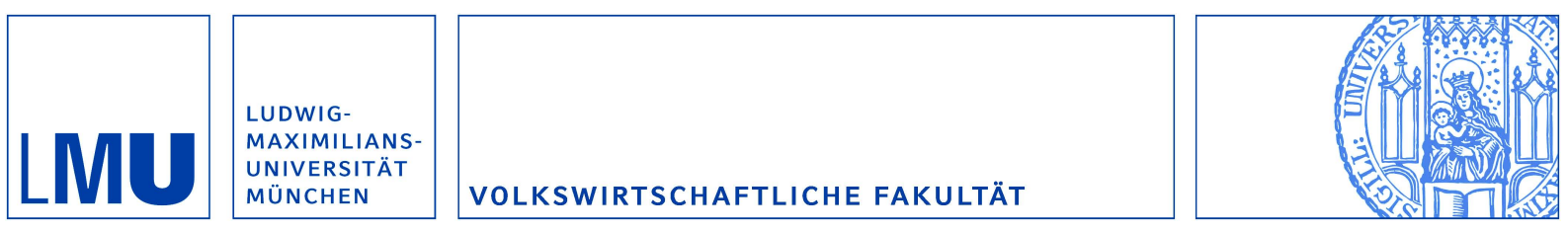

Grolleau, Gilles; Kocher, Martin G. und Sutan, Angela:

Cheating and loss aversion: do people lie more to avoid a loss?

Munich Discussion Paper No. 2014-42

Department of Economics

University of Munich

Volkswirtschaftliche Fakultät

Ludwig-Maximilians-Universitäł München

Online at https://doi.org/10.5282/ubm/epub.21387 


\title{
Cheating and loss aversion: do people lie more to avoid a loss?*
}

\author{
Gilles Grolleau $^{\S,+}$, Martin G. Kocher ${ }^{\#}$, and Angela Sutan ${ }^{+}$
}

\begin{abstract}
Does the extent of cheating depend on a proper reference point? We use a real effort task that implements a two (gain versus loss frame) times two (monitored performance versus unmonitored performance) between-subjects design to examine whether cheating is reference-dependent. Our experimental findings show that self-reported performance in the unmonitored condition is significantly higher than actual performance in the monitored condition-a clear indication for cheating. However, the level of cheating is by far higher in the loss frame than in the gain frame. Furthermore, men are much more strongly affected by the framing than women.
\end{abstract}

This version: August 25, 2014

JEL Code: C91, D03

Keywords: Cheating, Lying, Loss aversion, Experiment.

\footnotetext{
* We thank Lars Hornuf, Simeon Schudy and participants of the Florence 2013 Workshop on Behavioural and Experimental Economics for helpful comments and suggestions. Financial support from the PARI projects (Burgundy Regional Council) is also acknowledged. All remaining errors are ours.

${ }^{\S}$ LAMETA, UMR 1135 and LESSAC, 2 place Viala, 34060 Montpellier, France. E-mail: grolleau@ supagro.inra.fr.

\# Corresponding author University of Munich, Queensland University of Technology, and University of Gothenburg. Address: Department of Economics, University of Munich, Geschwister-Scholl-Platz 1, 80539 Munich, Germany. E-mail: martin.kocher@1rz.uni-muenchen.de.

${ }^{+}$LESSAC, ESC Dijon, and LAMETA, 29 rue Sambin, BP 50608, 21006 Dijon, France. E-mail: angelasutan@escdijon.eu; Tel. +33380725956
} 


\section{Introduction}

People frequently cheat or lie, especially to protect their self-interest or self-concept (Ariely, 2012). Two basic notions of cheating have been distinguished: On the one hand, people could just maximize their monetary outcomes, regardless of whether such an optimization requires lies or cheating. On the basis of a cost-benefit calculation, the would-be cheater decides whether to cheat or not (Becker, 1968). On the other hand, people could be basically honest and dislike lying or cheating, but circumstances may tempt them and can lead them to lie or cheat (Mazar et al., 2008). In other words, they trade off possible internalized norms or social norms not to lie or cheat (Kant, 1949) with the potential benefits (see also Gneezy, 2005; Dreber and Johannesson, 2008; Sánchez-Pagés and Vorsatz, 2009; Sutter, 2009; Abeler et al., 2014; Friesen and Gangadharan, 2012; Cappelen et al., 2013; Fischbacher and Föllmi-Heusi, 2013; Gibson et al., 2013; Gneezy et al., 2013; Lightle, 2013; Ariely et al., 2014).

In this paper, we are particularly interested in the circumstances that prompt people to cheat, keeping the costs and benefits of cheating constant. Such circumstances will be especially important in the design of behavioral mechanisms and institutions that reduce the amount or costs of cheating in situations involving limited verifiability or monitoring possibilities or in which the latter are (very) expensive. Our focus here is on the gain-loss frame (Kahneman and Tversky, 1979) of the cheating option. We hypothesize that it is perceptionally different to cheat in order to gain a certain advantage than to cheat in order to lose a certain advantage, even when the underlying outcome is exactly the same. We are not aware of any other studies in the economics literature with a similar research question.

Relevant real-world analogies to such framing differences or reference dependence pertaining to cheating readily come to mind. A recurrent example of cheating relates to welfare assistance. It is well-known that individuals can lie to benefit from welfare assistance. However, an individual can lose welfare benefits if she no longer fulfills the conditions required. Thus, individuals also lie not to lose welfare benefits they have been receiving. Recently, "a Shepherd resident who illegally collected more than $\$ 124,000$ in Social Security benefits for himself and his daughter admitted he got greedy and dodged agency requests about his employment. (...) Hofmann worked and was paid 'under the table' to hide his income and to avoid losing benefits [emphasis added] he was receiving from the Social Security Administration'. (Billings Gazette, 2009). In the same vein, there is anecdotal evidence that people are ready to lie or cheat to gain status, but especially not to lose face or status. A recent example is the case of Lance Armstrong who "had to lie about doping to keep winning" (Hall, 2013).

Based on the distinction between a gain frame and a loss frame, our main hypothesis for our empirical assessment is that people are more likely to lie to preserve a certain benefit (or avoid a loss) than to acquire it. We devise a laboratory experiment based on a real-effort task (Mazar et al., 2008; Gino et al., 2009) that addresses this issue in a $2 \times 2$-factorial, between-subject study design. The design 
varies the factors verifiability (monitoring performance is possible versus it is impossible) and the frame (cheating generates a perceptional gain versus it creates a perceptional loss). All other determinants are held constant, allowing us to causally assess our main hypothesis.

The gain-loss frame is introduced in the experiment by means of tangibility of payments. In the perceptional gain frame, participants in the experiments are paid according to their (reported) performance, after they have finished a certain number of real-effort tasks in a given amount of time. In the perceptional loss frame participants receive the maximum possible amount before they start with working on the real-effort tasks, knowing that they would have to return any money that they had not earned with their (reported) performance. In both cases the performance-based piece rate, i.e. the payment per correctly finished real-effort task, is announced in the beginning and common knowledge.

Our experimental results indeed indicate a very strong effect of advance payments. The level of cheating is almost doubled under advance payments compared to ex post payments. Since the incentive mechanism is linear, this implies that advance payments are about twice as expensive as ex post payments in the two conditions that allow for lying. Not surprisingly, the timing of payment has no effect at all on performance when monitoring is possible. However, as soon as monitoring is credibly made impossible, reported performance increases with ex post payment, but much more so with advance payment. We interpret the results in terms of gain-loss framing of payments induced through tangibility of payments in the advance payment setting.

The setup we implement in our real-effort experiment is related to a work environment with incomplete contracts and non-verifiability. It provides evidence that the positive view of advance payments as a means to increase effort reciprocity (e.g., Fryer et al., 2009) has to be questioned. Advance payments under certain circumstances may trigger higher levels of cheating or fraudulent behavior. While there is of course evidence on positive reciprocity stemming from advance payments, one should be careful in ascribing only positive consequences to them. Obviously, the extent to which potential effort-enhancing effects and potential cheating effects of advance payments occur depend on the perception of decision makers. Likewise, whether and when potential cheating effects might offset incentive effects is an open research question. At least for our setup, we were unable to detect a significantly positive incentive effect of advance payments, but we observe a large negative cheating effect.

The remainder of our paper is organized as follows. The following section provides an overview of the related literature and formulates our main hypothesis. Section 3 presents the empirical strategy that we employ. The fourth section discusses the results of our experiment, and Section 5 concludes the paper. 


\section{Overview of related literature}

The traditional economic model - in the spirit of Becker (1968) - has assumed that lying or cheating is only an issue of maximizing monetary outcomes. People lie or cheat if these actions increase their expected utility. However, more recently, a sizeable and quickly growing number of studies have addressed several aspects of lying or cheating in an economic context.

We do not intend to survey the entire literature here (see, for instance, Ariely, 2012; Abeler et al. 2014); it has been growing quickly over the last couple of years. Most of the economic literature on lying and cheating started with an assessment of whether people follow a Beckerian approach (and lie to the full extent possible) or whether people moderate the extent of their lying and cheating. Indeed, on average, the latter is true, i.e., people do not cheat as much as they can even if they forgo significant amounts of money if they remain honest (see, e.g., Gneezy, 2005; Sutter, 2009; Fischbacher and Föllmi-Heusi, 2013). Reasons for restraining one's cheating and lying are numerous. Abstracting from the obvious influence of the detection probability (Rowatt et al., 1998; Lundquist et al., 2009), there might be a social norm or an internalized norm not to lie or cheat, and people might experience negative emotions when they lie or cheat (Batigalli et al., 2013). If that is the case, people are lying averse either of social image concerns or of self-image concerns. The combination of these concerns that might strongly depend on the context (think of an individual tax declaration versus a confession in front of a catholic priest) determines the extent of lying behavior in combination with an individual's inclination to be honest and truthful. ${ }^{1}$ Consequently, the next issue in the experimental economics literature on lying and cheating was an analysis of the determinants that promote or restrict lying behavior. Numerous circumstances that can contribute to a higher propensity of lying have been examined. Without purporting to be exhaustive here, the following determinants have been mentioned: people lie more when stakes and expected benefits are high (Boles at el., 2000), when the characteristics are prone to measurement error (Toma et al., 2008), when the benefits from cheating are shared (Wiltermuth, 2011), if people expect not to be believed when they report private information in presence of an opportunity (Sutter, 2009), if the context of the lie could play a role (Cappelen et al., 2013), when others lie (Gino et al., 2009), and after negative previous experience (Houser et al., 2012).

Regarding our main interest of research, the interaction of gain versus loss frames and the inclination to lie, there is a couple of more closely related paper. Cameron and Miller (2009) implement an experiment in which anagrams have to be solved. Instead of advance and ex post payments they just frame the situation in terms of potential gains or losses; further, the monetary incentives were quite low, and they do not analyze the possibility of an interaction between the

\footnotetext{
${ }^{1}$ Sometime lying may even be the norm. Such lies are also called 'white lies' (see, e.g., Erat and Gneezy, 2012). In the following, we abstract from such lying motives. We also disregard the large literature on promise keeping (e.g., Charness and Dufwenberg, 2006; Vanberg, 2008).
} 
gain/loss frame and the possibility to cheat or not. However, their main result is in line with our hypothesis, i.e. that the loss frame has a tendency to increase cheating behavior.

Gravert (2013) provides a link between entitlements and stealing. In her experiment she finds that participants who had earned their payoff according to performance were much more likely to take the (undeserved) maximum payoff than participants in a random payment scheme. Supposedly, an endowment effect has an impact on the inclination to cheat. Linking the endowment effect to reference-dependence provides the connection between her study and ours. A similar effect is reported for goal-setting in Schweitzer et al. (2004). They found in a laboratory experiment that unmet goals lead to a higher rate of unethical behavior. In Jacobsen and Piovesan (2014), a tax frame is combined with a cheating option. Expectedly, the tax frame compared to a neutral frame is used as an excuse to rationalize cheating behavior. The paper shows that framing is relevant for the degree of cheating, but it does not vary the framing over gains and losses.

Finally, Levitt et al. (2012) implement a field experiment to examine the effect of incentives for teachers on performance of students. They found that students trained by teachers who were given the bonuses in the beginning of the year obtained better scores than those trained by teachers that received the bonuses at the end of the year. In other words, the prospect of losing a reward seems to motivate individuals to perform better than the possibility of gaining the same reward after the test ends. In their paper, they do not take cheating into account as a potentially detrimental force, but in a previous paper by Jacob and Levitt (2003) they note that the "observed frequency of cheating appears to respond strongly to relatively minor changes in incentives".

In the next section, we design an experiment to test whether cheating decisions differ in an environment that includes financial incentives framed either as a gain or as a loss. Given that the neoclassical cost-benefit result is identical in the two framings, we can detect whether the framing influences cheating behavior.

\section{Experimental design, identification strategy, and hypotheses}

We use an experimental design for our real-effort laboratory experiment that has been introduced by Mazar et al. (2008). More precisely, we implement a 2 (gain or loss) x 2 (monitored performance or unmonitored performance) between-subjects design with a total of 259 experimental participants (see Table 1). Individuals in the laboratory are given a sheet of paper with a series of 20 different pairs of matrices containing nine non-integer numbers each and are asked to find in each of the pairs two numbers that add up to exactly 10 (see the Appendix for an example of a matrix sheet). In written instructions (see an example, for our experimental instructions for the cheating condition in the 
Appendix), participants are told that they have five minutes to solve as many of the pairs as possible and that they get paid based on how many they solve correctly. Each correctly solved pair is worth $1.50 €$; this piece rate is clearly stated in the instructions.

Table 1. 2x2-factorial, between-subject experimental design

\begin{tabular}{ccc}
\hline & $\begin{array}{c}\text { Monitored performance } \\
\text { (No cheating opportunity) }\end{array}$ & $\begin{array}{c}\text { Unmonitored performance } \\
\text { (Cheating opportunity) }\end{array}$ \\
\hline $\begin{array}{c}\text { Gain frame (payment ex post; } \\
\text { according to (self-reported) }\end{array}$ & $T 1$ : Control treatment & T3: Level of cheating in gain \\
performance) & $(\mathrm{N}=71)$ & frame \\
$(\mathrm{N}=79)$ \\
$\begin{array}{c}\text { Loss frame (payment in advance } \\
\text { and reimbursement according to } \\
\text { (self-reported) performance) }\end{array}$ & $\begin{array}{c}\text { 2: Effect of loss frame on } \\
\text { performance } \\
(\mathrm{N}=43)\end{array}$ & $\begin{array}{c}\text { T4: Level of cheating in loss } \\
\text { frame } \\
\text { (N=66) }\end{array}$ \\
\hline \hline
\end{tabular}

Note: $\mathrm{N}$ is the number of observations; $\mathrm{T}$ stands for Treatment.

People can cheat on the matrix task in the two "cheating conditions" because of a "shredder" announced in the beginning. Subjects are asked to count their correct answers on their own and then put their work sheets through a paper shredder at the back of the room. They then state to the experimenter how many pairs of matrices they solved correctly and get paid accordingly. Regardless of whether the shredder condition applied or whether the experimenter could verify the number of correctly solved matrices the remuneration for each solved pair was always $1.50 €$. After verifying the number of solved matrices by the experimenter in the "non-cheating conditions", the sheets of papers were also shredded.

Our gain frame corresponds to payment of the participants after they solve the matrix task according to the number of solved matrices. The loss frame is equivalent to payment of the participants in advance, asking for the excess amount to be given back to the experimenter at the end of the experiment. In the loss frame, we gave each participant the maximum possible amount of $30 €$ (20 pairs time $1.50 €)$ in advance in cash.

Introducing sufficient levels of loss aversion in a standard utility model would immediately provide as a theoretical result our main hypothesis, i.e., as indicated earlier, that the gain/loss frame will impact cheating behavior. Since the result is obvious, we omit a formal model here. As already discussed, we expect to observe a higher (reported) performance in loss-framed treatments than in gain-framed treatments. Moreover, as in our setting there are no exogenous costs related to lying (full anonymity, no possibility of detection, etc.), the standard prediction is that, when given the opportunity to lie, people will take it, as it corresponds to profit maximization: correspondingly, we expect the (reported) unmonitored performance to exceed the monitored performance also in the gain frame. This prediction would lead to a reported performance of solved matrixes up to the maximum (i.e. 20 pairs). However, several papers reported non-maximal levels of lying in comparable experimental situations (Mazar at al. 2008; Fischbacher and Föllmi-Heusi, 2013; Abeler et al. 2014), 
and several theoretical papers (starting with Crawford and Sobel, 1982) argued in favor of a tradeoff between psychological costs of lying and monetary benefits. Hence, our expectation is that lying levels are, on average, bounded away from the maximum. Our results could also be gender-dependent. Several experimental studies report women to be more honest than men (Dreber and Johannesson, 2008; Houser et al., 2012). However, such a gender effect could be modulated by gender-sensitive performance in and gender-specific implications of the task and, thus, the direction of the overall effect is an empirical question.

To sum up, we test the following three main hypotheses in our experiment:

Hypothesis 1: A higher performance will be self-reported in loss frames as compared to gain frames.

Hypothesis 2: A higher unmonitored performance will be reported than the actual monitored performance both in the gain frame and the loss frame. Yet, the self-reported unmonitored performance will not be at the maximum.

Hypothesis 3: A higher performance will be self-reported by men as compared to women.

By comparing performance in $\mathrm{T} 1$ and $\mathrm{T} 2$, we are able to explore whether a loss frame in itself improves monitored performance ceteris paribus, as indicated by parts of the previous literature. By comparing the level of cheating between $\mathrm{T} 3$ and $\mathrm{T} 4$, we are able to evaluate to what extent a loss frame pushes people to behave more dishonestly than the gain frame. This will fully test Hypothesis 1 . By comparing performance in T3 versus T1 and T4 versus T2 we test Hypothesis 2. Hypothesis 3 will be tested for all our treatments.

The experiment was conducted in the LESSAC laboratory in Dijon in September and October 2012. A total number of 259 subjects from various academic backgrounds were recruited via ORSEE (Greiner, 2004). Subjects remained anonymous throughout the experiment, and cash payments were made privately. Gender of our subjects is recorded by the experimenter when paying them. An experimental session lasted for about 30 minutes, on average. Subjects earned an average of $€ 8.60$ (in LESSAC, show-up fees are not commonly used). Importantly, all sessions have been conducted by the same female experimenter.

\section{Results and discussion}

We start by looking at the main treatment effects. Table 2 provides a descriptive overview of our results. First, it is worthwhile noting that we do not find a significant different between ex ante and ex 
post payment with monitored performance (two-sided Mann-Whitney-U-test; $p=0.89$ ). If you want, there is no additional motivational effect of putting ex-ante money on the table in our setting.

Table 2. Number of pairs of matrices (reported as) solved

\begin{tabular}{ccc}
\hline & $\begin{array}{c}\text { Monitored performance } \\
\text { (No cheating opportunity) }\end{array}$ & $\begin{array}{c}\text { Unmonitored performance } \\
\text { (Cheating opportunity) }\end{array}$ \\
\hline Gain frame (payment ex post; & 3.93 & 5.42 \\
according to performance) & $(2.46)$ & $(4.29)$ \\
& & \\
$\begin{array}{c}\text { Loss frame (payment in advance } \\
\text { and reimbursement according to } \\
\text { (self-reported) performance) }\end{array}$ & 4.00 & 9.56 \\
\hline \hline Note: Standard deviation in brackets. & $(2.83)$ & $(6.75)$ \\
\hline
\end{tabular}

Second, we observe a considerable extent of cheating. This is perfectly in line with the literature. Comparing the gain frame under monitored and unmonitored performance, we obtain an increase in the number of pairs of matrices (reported as) solved of about 38\% from 3.93, on average, to 5.42 (twosided Mann-Whitney-U-test; $p=0.02$ ). Our design allows us to interpret the difference as the consequence of cheating by our participants. However, the most important comparison for our study is between monitored and unmonitored performance in the loss frame. Here the increase in the number of pairs of matrices (reported as) solved is far more than 100\%. The difference between 4.00 and 9.56 matrices, on average, is highly significant (two-sided Mann-Whitney-U-test; $\mathrm{p}<0.001$ ).

Finally, it immediately clear that the frame also matters in the unmonitored conditions, i.e. when there is an opportunity to cheat. While the increase in performance from the gain to the loss frame is negligible with monitoring, it is strong without monitoring. The reported number of solved matrices rises from 5.42 to 9.56, on average. The difference is highly significant (two-sided Mann-Whitney-Utest; $p<0.001)$. Since we control for all relevant confounds, the average differences can only be attributed to differences in the extent of cheating by our participants in the real-effort task.

It is also interesting to look at the distributions of the reported number of matrices solved (see Figure 1). Whereas very few participants solve more than ten matrices under monitoring, many people report ten to 20 solved matrices under no monitoring. Interestingly, only about $7 \%$ of the participants report the maximum performance of 20 solved matrices in the ex ante payment treatment without monitoring. Thus, we confirm results from previous studies (e.g., Föllmi-Heusi and Fischbacher, 2013) which imply that few people lie to the full possible extent (maximizing their payoffs). Instead, on average, they choose levels of performance that do not seem outrageous. Whether this behavior is due to self-image concerns, social image concerns, or uncertain beliefs regarding the experimenter's response to outrageous performance reports, is an interesting question that cannot be answered in our setup. 


\section{Figure 2. Number of pairs of matrices (reported as) solved - distribution}

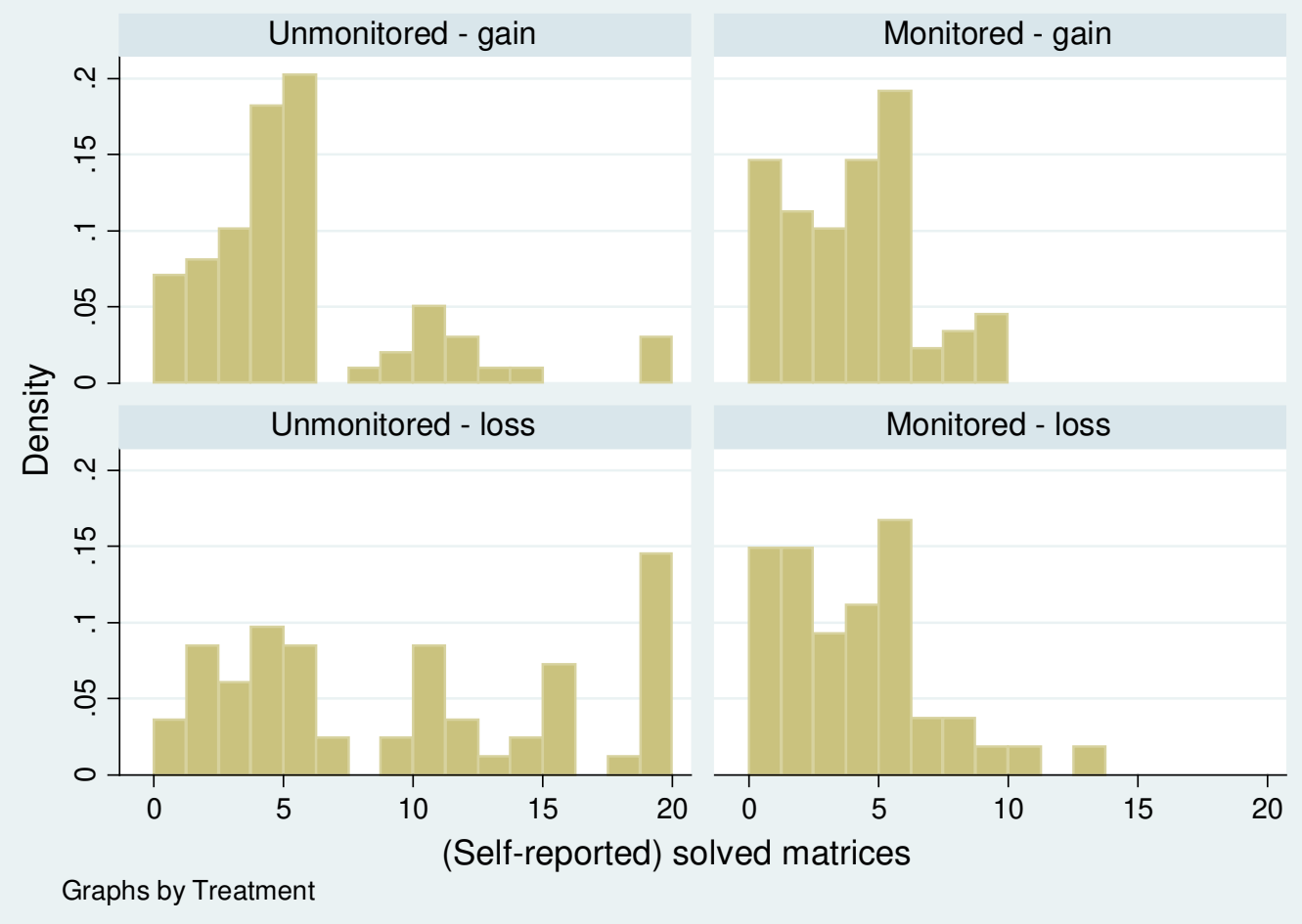

Result 1 (related to Hypothesis 1): Cheating is significantly more often observed in the loss frame than in the gain frame: (self-reported) performance increases from 5.42 to 9.56 solved matrices.

Result 2 (related to Hypothesis 2): Without monitoring, the self-reported performance is significantly higher than the actual performance both in the gain and in the loss frame. However, cheating is not going to the maximal, payoff-maximizing level.

We now address potential gender effects, stressing that the analysis is exploratory. Table 3 provides an overview of averages. Women's actual performance under monitoring is slightly positively affected by the framing going from the gain to the loss frame, while men's real performance is slightly negatively affected. This result is consistent with previous studies on women perceiving advance payments as a signal of trust and reciprocating trust more (see, for instance, Aguiar et al., 2009), but the magnitudes in our setup are not very large.

The effect of a loss frame on reported performance seems stronger for men than for women (for men, we observe an increase from 5.50 to 11.94 , while for women the increase only goes from 5.24 to 6.87). Indeed, the difference is insignificant for females (two-sided Mann-Whitney-U-test; $p>0.35$ ), but highly significant for males (two-sided Mann-Whitney-U-test; $p<0.01$ ). Whether this gender 
difference in response to the framing is a consequence of the task that seems to be easier for men than for women is a question that cannot be answered here. There are other explanations for the gender effect, but none of them is entirely convincing. For instance, women could be less loss averse than men, but if there is at all a gender difference in loss aversion in lottery decisions, it seems to go in the opposite direction (Schmidt and Traub, 2002). It is impossible to rule out - not only in our experiment, but in any comparable cheating experiment - that the participants perceive a certain risk that outrageous claims will not be accepted by the experimenter. If that is the case different risk attitudes between males and females would be an explanation for the observed gender differences. It is probably not necessary to add here that we did everything to credibly signal to our participants that all claims will be accepted. Similarly, the specific task might induce males and females to form different beliefs over the expectations regarding performance held by the experimenter. Again, formally these expectations should not matter at all, but it is impossible to control for the perception of participants in our setup.

Table 3. Number of pairs of matrices reported as solved

\begin{tabular}{ccccccc}
\hline $\begin{array}{c}\text { Monitored } \\
\text { performance } \\
\text { (all) }\end{array}$ & $\begin{array}{c}\text { Monitored } \\
\text { performance } \\
\text { FEMALE }\end{array}$ & $\begin{array}{c}\text { Monitored } \\
\text { performance } \\
\text { MALE }\end{array}$ & $\begin{array}{c}\text { Unmonitored } \\
\text { performance } \\
\text { (all) }\end{array}$ & $\begin{array}{c}\text { Unmonitored } \\
\text { performance } \\
\text { FEMALE }\end{array}$ & $\begin{array}{c}\text { Unmonitored } \\
\text { performance } \\
\text { MALE }\end{array}$ \\
\hline Gain frame & $\mathbf{3 . 9 3}$ & $3.09(34)$ & $4.70(37)$ & $\mathbf{5 . 4 2}$ & $5.24(42)$ & $5.50(36)$ \\
Loss frame & $\mathbf{4}$ & $3.58(26)$ & $4.65(17)$ & $\mathbf{9 . 5 6}$ & $6.87(31)$ & $11.94(35)$ \\
\hline \hline
\end{tabular}

Note: In bold, same information (averages) as in Table 2. Number of observations in parentheses. Gender information is missing for one observation.

Result 3 (related to Hypothesis 3): Males respond much stronger to the framing in the unmonitored conditions than females.

All our non-parametric results are supported when using Tobit regression that takes the censoring of the dependent variable, the (self-reported) number of solved pairs of matrices, into account. ${ }^{2}$ Table 4 gives the results of three models, one for females only, one for males only, and one for both genders, introducing the appropriate dummy variables. The coefficients reveal that both genders cheat when it is possible (under no monitoring), but the extent of cheating is higher for men than for women. As already discussed above, males react much more strongly to the gain/loss frame than females. In contrast to the non-parametric results, the frame has a weakly significant impact on the performance of females, but the interaction effect of the frame with the monitoring condition is still insignificant.

Table 4. Tobit regression explaining the (self-reported) number of pairs of matrices solved

\footnotetext{
${ }^{2}$ OLS regressions provide qualitatively the same results and the same levels of significance.
} 


\begin{tabular}{|c|c|c|c|}
\hline (Self-reported) number of pairs of matrices solved & Female & Male & All \\
\hline Female & - & - & $\begin{array}{c}-5.64 * * * \\
(1.17)\end{array}$ \\
\hline Gain frame & $\begin{array}{l}-1.69 * \\
(1.03)\end{array}$ & $\begin{array}{c}-7.13 * * * \\
(1.21)\end{array}$ & $\begin{array}{c}-7.06 * * * \\
(1.13)\end{array}$ \\
\hline Monitoring possible & $\begin{array}{c}-3.44 * * * \\
(1.16)\end{array}$ & $\begin{array}{c}-7.88 * * * \\
(1.50)\end{array}$ & $\begin{array}{c}-7.82 * * * \\
(1.39)\end{array}$ \\
\hline Gain frame $\times$ Monitoring possible & $\begin{array}{c}1.24 \\
(1.54)\end{array}$ & $\begin{array}{c}7.19 * * * \\
(1.91)\end{array}$ & $\begin{array}{c}7.11 * * * \\
(1.77)\end{array}$ \\
\hline Female $\times$ Gain frame & - & - & $\begin{array}{c}5.36 * * * \\
(1.59)\end{array}$ \\
\hline Female $\times$ Monitoring possible & - & - & $\begin{array}{c}4.36 * * \\
(1.87)\end{array}$ \\
\hline Female $\times$ Gain frame $\times$ Monitoring possible & - & - & $\begin{array}{c}-5.86 * * \\
(2.43)\end{array}$ \\
\hline Constant & $\begin{array}{c}6.83 * * * \\
(0.78) \\
\end{array}$ & $\begin{array}{c}12.53 * * * \\
(0.87)\end{array}$ & $\begin{array}{c}12.47 * * * \\
(0.81) \\
\end{array}$ \\
\hline Log likelihood & -363.20 & -350.50 & -718.85 \\
\hline No. of observations & 133 (120 unsc.) & 125 (111 unsc.) & 258 (231 unsc.) \\
\hline
\end{tabular}

Notes: ${ }^{*} p<.1,{ }^{* * *} p<.05,{ }^{* * * *} p<.01$. Standard errors are reported in parentheses. Unsc. $=$ uncensored.

\section{Discussion and conclusion}

We have shown that ethical decision making is vulnerable to the powers of framing. Many people lie more to avoid a loss than to acquire a similar gain. Interestingly, men react much more to the framing than women. There are at least two mutually non-exclusive rationales that can explain why we observe such a strong framing effect in our experiment. First, the loss frame (advance payments) can provide individuals with a construal that makes them feel entitled to the money received at the beginning. Indeed, dishonest behavior could be just a way to protect this entitlement, making dishonesty more acceptable than in the gain frame condition. In other words, the money provided in advance serves as a reference point that is higher than the reference point of participants in the gain frame. In line with prospect theory and given that dishonesty is frequently viewed as risky behavior, individuals in the loss frame (gain frame) are more likely to act risk-seeking (risk averse) (Kahneman and Tversky, 1979; see also Brewer and Kramer, 1986), i.e. they cheat more. Formally, though, there was no risk involved in our experiment.

A second rationale relates to the insight that seeking to avoid a loss could make an unethical decision more acceptable not only by the individual but also by third parties. If the norm of not cheating is less strict in the loss domain, many lying aversion models would predict more lying under losses than under gains. One emotional reason for such an asymmetry could be a reduced level of guilt felt, when lying under losses than when lying under gains. Somewhat relatedly, Kahneman et al. (1986) showed that individuals are more willing to accept company decisions that will otherwise be considered as unethical if the company attempts to compensate for losses than if it follows the same 
action in order to increase its profits. There is some evidence that guilt could be perceived differently by men and women (Ludwig and Thoma, 2014), which could explain the strong gender difference that we observe for the framing.

Our main finding seems relevant in several ways. First, it may help to identify circumstances under which people are more tempted to cheat. Indeed, when individuals are in a situation that is construed as a possible loss from a reference point (e.g., being fired, losing welfare benefits, or retaining a customer), they seem to be more likely to adopt unethical behaviors compared to a situation framed as a gain. For instance, if a person's situation changes, and the change increases a person's tax liability compared to the previous years, this person might be tempted to a greater extent to evade taxes than someone who is supposed to pay the same tax amount as in the preceding years.

Second, if resources for monitoring are limited, ceteris paribus, it might be more efficient to target individuals who risk losing something rather than individuals who risk winning something. For instance, when looking at welfare fraud, our findings indicate that monitoring strategies should focus on those who are already beneficiaries and stand to lose parts of their benefits. In sports contests, antidoping authorities could focus their efforts slightly more on previous winners and record-holders that stand to lose their status or titles rather than on newcomers. Importantly, these are often cheating environments that are interactive; the level of monitoring is not completely exogenous but chosen by an authority. Hence, the results from our individual (non-interactive) working task have to be interpreted cautiously and cannot directly be applied to all relevant interactive situations. Furthermore, focusing monitoring efforts on specific groups might be perceived as unfair or inappropriate in some situations (e.g., ethnic profiling).

Third, a natural implication of our result for decision makers is to devote enough attention to gain/loss perception and to potentially unintended effects from the framing. Consequently, an inexpensive policy (whenever available) with first-order effects on cheating would be to reframe situations in order to avoid loss framing.

Our findings also point toward two additional interesting issues. A loss frame does not improve actual performance in our case, which means that principals seeking to improve performance of agents ought to be cautious in relying on loss frames as a performance-enhancing device, even in the absence of cheating opportunities. Second, gender differences are not trivial. Females seem to cheat to a lesser degree than males, even though cheating in the unmonitored performance conditions is still substantial among women, but they seem to be much less prone to the gain/loss framing differentials than men.

Several extensions seem to present themselves as relevant for future research: For instance, it would be worthwhile analyzing whether the gain/loss difference in cheating is mainly driven by the perception of social norms depending on a reference point or by internalized reactions such as difference in feelings of guilt. There might even be other explanations for the observed difference that we could not cover in our non-interactive setting. Hence, extending our experimental design to a fully 
interactive (game) environment could be interesting. Field experiments using gain/loss framing as a device to limit cheating would be another interesting opportunity. Finally, the large gender differences in the reaction to the gain/loss framing are surprising. If at all, one would have expected women to be more sensitive to the framing than men (as experimental results from decision making under risk seem to suggest that women tend to be more loss averse than men). We have only post hoc explanations for this finding, and it would be good to, first, have it substantiated in future research and, then, have its causes analyzed in greater detail. Obviously, it would be worthwhile to also look whether our main result is robust to different socio-cultural settings (see, e.g., Mann et al., 2014), even though there is no a priori reason to believe that our participants, French university students, are somewhat more particular than other cohorts of usual experimental participants in the experimental economics laboratories around the world. 


\section{References}

Abeler, J., Becker, A., Falk, A. (2014). Representative evidence on lying costs. Journal of Public Economics 113, 96-104.

Aguiar, F., Brañas-Garza, P., Cobo-Reyes, R., Jimenez, N., Miller, L.M. (2009). Are women expected to be more generous? Experimental Economics 12, 93-98.

Ariely, D. (2012). The Honest Truth About Dishonesty: How We Lie to Everyone - Especially Ourselves. Harper, New York.

Ariely, D., Garcia-Rada, X., Hornuf, L., Mann, H. (2014). The (true) legacy of two really existing economic systems. Working Paper, Duke University.

Batigalli, P., Dufwenberg, M., Charness, G. (2013). Deception: the role of guilt. Journal of Economic Behavior and Organization 93, 227-232.

Becker, G.S. (1968). Crime and punishment: an economic approach. Journal of Political Economy 76, 169-217.

Billings Gazette (2009). December, 21, http://billingsgazette.com/news/local/crime-andcourts/article_63e7610a-ee8e-11de-abc4 001cc4c03286.html.

Brewer, M.B., Kramer, R.M. (1986). Choice behavior in social dilemmas: effects of social identity, group size, and decision framing. Journal of Personality and Social Psychology 50, 543-549.

Cameron, J.S., Miller, D.T. (2009). Different ethical standards in gain versus loss frames. In D. de Cremer (ed.), Psychological Perspectives on Ethical Behavior and Decision Making. Information Age Publishing, Charlotte, NC, 91-106.

Cappelen, A.W., Konow, J., Sørensen, E.Ø., Tungodden, B. (2013). Just luck: an experimental study of risk-taking and fairness. The American Economic Review 103, 1398-1413.

Charness, G., Dufwenberg, M. (2006). Promises and partnership. Econometrica 74, 1579-1601.

Crawford, V.P., Sobel, J. (1982). Strategic information transmission. Econometrica 50, 1431-1451.

Dreber, A., Johannesson, M. (2008). Gender differences in deception. Economics Letters 99, 197-199.

Erat, S., Gneezy, U. (2012). White lies. Management Science 58, 723-733.

Fischbacher, U., Föllmi-Heusi, F. (2013). Lies in disguise—an experimental study on cheating. Journal of the European Economic Association 11, 525-547.

Friesen, L., Gangadharan, L. (2013). Designing self-reporting regimes to encourage truth telling: an experimental study. Journal of Economic Behavior and Organization 94, 90-102.

Fryer, R., Levitt, S.D., List, J., Sadoff, S (2009). Enhancing the efficacy of teacher incentives through loss aversion: a field experiment, NBER Working Paper No. 18237.

Gibson, R., Tanner, C., Wagner, A.F. (2013). Preferences for truthfulness: heterogeneity among and within individuals. American Economic Review 103, 532-548.

Gino, F., Gu, J., Zhong, C.B. (2009). Contagion or restitution? When bad apples can motivate ethical behavior. Journal of Experimental Social Psychology 45, 1299-1302. 
Gneezy, U. (2005). Deception: the role of consequences. American Economic Review 9, 384-394.

Gneezy, U., Rockenbach, B., Serra-Garcia, M. (2013). Measuring lying aversion. Journal of Economic Behavior and Organization 93, 293-300.

Gravert, C. (2013). How luck and performance affect stealing. Journal of Economic Behavior and Organization 93, 301-304.

Greiner, B., 2004. An online recruitment system for economic experiment. In Kremer, K., Macho, V. (eds.), Forschung und wissenschaftliches Rechnen 2003. GWDG Bericht 63, Göttingen, 79-93.

Hall, M. (2013). The man who fell to earth. Texas Monthly, March, http://www.texasmonthly.com/story/man-who-fell-earth/page/0/3.

Houser, D., Vetter, S., Winter, J. (2012). Fairness and cheating. European Economic Review 56, $1645-$ 1655.

Jacob, B.A., Levitt, S.D. (2003). Rotten apples: an investigation of the prevalence and predictors of teacher cheating. Quarterly Journal of Economics 118, 843-877.

Jacobsen, C., Piovesan, M. (2014). Tax me if you can: an artefactual field experiment on dishonesty. Mimeograph.

Kahneman, D., Knetsch, I., Thaler, R. (1986). Fairness as a constraint on profit seeking. American Economic Review 76, 728-741.

Kahneman, D., Tversky, A. (1979). Prospect theory: an analysis of decision under risk. Econometrica 47, 263-292.

Kant, I. (1949). Critique of practical reason, and other writings in moral philosophy. University of Chicago Press, Chicago.

Levitt, S.D., List, J., Neckermann, S., Sadoff, S. (2012). The behavioralist goes to school: leveraging behavioral economics to improve educational performance. NBER Working Paper No. 18165.

Lightle, J.P. (2013). Harmful lie aversion and lie discovery in noisy expert advice games. Journal of Economic Behavior and Organization 93, 347-362.

Ludwig, S., Thoma, C. (2014). Do Women have more shame than men? An experiment on selfassessment and the shame of overestimating oneself. Working Paper, University of Munich.

Lundquist, T., Ellingsen, T., Gribbe, E., Johannesson, M. (2009). The aversion to lying. Journal of Economic Behavior and Organization 70, 81-92.

Mann, H., Garcia-Rada, X., Hornuf, L., Tafurt, J., Ariely, D. (2014). Similar patterns of cheating across cultures. Mimeograph.

Mazar, N., Amir, O., Ariely, D. (2008). The dishonesty of honest people: A theory of self-concept maintenance. Journal of Marketing Research 45, 633-644.

Rowatt, W.C., Cunningham, M.R., Druen, P.B. (1999). Lying to get a date: The effect of facial physical attractiveness on the willingness to deceive prospective dating partners. Journal of Social and Personal Relationships 16, 209-223. 
Sánchez-Pagés, S., Vorsatz, M. (2009). Enjoy the silence: an experiment on truth-telling. Experimental Economics 12, 220-241.

Schmidt, U., Traub S. (2002). An experimental test of loss aversion. Journal of Risk and Uncertainty $25,233-249$.

Schweitzer, M.E., Ordóñez, L., Douma, B. (2004). Goal setting as a motivator of unethical behavior. Academy of Management Journal 47, 422-432.

Sutter, M. (2009). Deception through telling the truth? Experimental evidence from individuals and teams. Economic Journal 119, 47-60.

Toma, C, Hancock, J., Ellison, N. (2008), Separating fact from fiction: an examination of deceptive self-presentation in online dating profiles. Personality and Social Psychology Bulletin 34, 10231036.

Tversky, A, Kahneman, D. (1991). Loss aversion in riskless choice: a reference-dependent model. Quarterly Journal of Economics 106, 1039-1061.

Vanberg, C. (2008). Why do people keep their promises? An experimental test of two explanations. Econometrica 76, 1467-1480.

Wiltermuth, S. (2011). Cheating more when the spoils are split. Organizational Behavior and Human Decision Processes 115, 157-168. 


\section{Appendix (for online publication)}

Experimental instructions (translated from French; condition without monitoring and ex ante payment)

\section{Welcome!}

\section{General information}

In this experiment you are asked to complete a simple task. When you entered the room, you received this instructions, an envelope containing 30 euros, and two others sheets of paper labeled TASK and RESULT.

Please verify the amount of 30 euros in your envelope.

If you succeed to complete the task, you can keep the 30 euros. Otherwise, the amount will be reduced according to your performance on this task.

\section{Your task}

You have 5 minutes to find, in each pair of the following 20 pairs of matrices, which two numbers add up to exactly 10 (one number from matrix 1 plus one number from matrix 2).

Please circle the numbers that add up to 10 in each pair of matrices clearly.

\section{Earnings}

If you solve the task correctly for all 20 pairs of matrices, you can keep the 30 euros.

Otherwise, for every unsolved/wrong pair, 1.5 euro will be subtracted from the 30 euros. For instance, if you solved correctly 14 pairs of matrices, and had 6 incorrect pairs of matrices, you will end up with $30-6 * 1,5=21$ euros instead of 30 .

Once the 5 minutes are finished, please report on the sheet RESULTS the number of correct answers you had. Substract the corresponding number of euros for the number of unsolved pairs of matrices from the envelope, keep the earned amount with you, and give back the envelope to the experimenter with the remaining money. Destroy your TASK sheet through the paper shredder in the back of the room.

Give back to the monitor only your RESULT sheet and the remaining money.

If you have any questions, please let us know.

\section{Good luck!}


Examples for pairs of matrices (not provided in instructions)

\begin{tabular}{|c|c|c|}
\hline 5,11 & 5,97 & 4,36 \\
\hline 5,02 & 4,84 & 4,37 \\
\hline 5,26 & 4,61 & 5,6 \\
\hline 4,71 & 5,46 & 5,98 \\
\hline
\end{tabular}

\begin{tabular}{|c|c|c|}
\hline 4,09 & 3,33 & 5,44 \\
\hline 5,08 & 6,06 & 6,03 \\
\hline 4,84 & 4,49 & 4,82 \\
\hline 6,19 & 4,74 & 4,4 \\
\hline
\end{tabular}

matrice
\begin{tabular}{|l|l|l|}
\hline 5,72 & 4,25 & 4,81 \\
\hline 4 & 4,8 & 5,49 \\
\hline 4,12 & 4,43 & 5,77 \\
\hline 4,14 & 4,35 & 5,11 \\
\hline
\end{tabular}

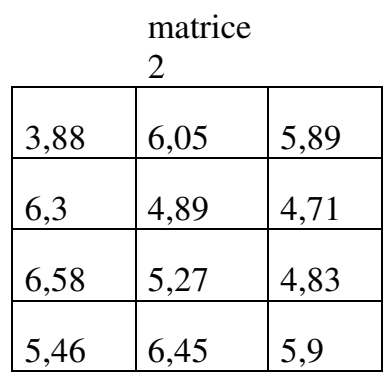

matrice
\begin{tabular}{|l|l|l|}
\hline 4,12 & 5,29 & 4,99 \\
\hline 4,73 & 4,65 & 4,28 \\
\hline 4,03 & 4,07 & 4,94 \\
\hline 5,56 & 5,17 & 4 \\
\hline
\end{tabular}

\begin{tabular}{|c|c|c|}
\hline \multicolumn{3}{|c|}{$\begin{array}{l}\text { matrice } \\
2\end{array}$} \\
\hline 5,78 & 4,11 & 4,31 \\
\hline 5,47 & 5,95 & 6,02 \\
\hline 5,66 & 5,73 & 5,97 \\
\hline 4,94 & 4,23 & 5,1 \\
\hline
\end{tabular}

matrice
1
\begin{tabular}{|l|l|l|}
\hline 4,13 & 5,79 & 5,77 \\
\hline 5,15 & 5,7 & 5,4 \\
\hline 5,68 & 4,35 & 4,92 \\
\hline 4,6 & 4,33 & 5,34 \\
\hline
\end{tabular}

\begin{tabular}{l}
\multicolumn{1}{c}{ matrice } \\
\begin{tabular}{|l|l|l|}
\hline 6,17 & 4,31 & 4,3 \\
\hline 5,45 & 4,66 & 4,4 \\
\hline 3,82 & 5,45 & 4,58 \\
\hline 5,9 & 6,37 & 3,96 \\
\hline
\end{tabular}
\end{tabular}

matrice
\begin{tabular}{|l|l|l|}
\hline 4,47 & 5,63 & 5,9 \\
\hline 5,39 & 5,24 & 4,44 \\
\hline 4,56 & 4,84 & 4,69 \\
\hline 4,07 & 4,79 & 4,4 \\
\hline
\end{tabular}

\begin{tabular}{|c|c|c|}
\hline \multicolumn{3}{|c|}{$\begin{array}{l}\text { matrice } \\
2\end{array}$} \\
\hline 4,63 & 4,87 & 4,8 \\
\hline 3,91 & 4,86 & 5,96 \\
\hline 6,44 & 5,96 & 5,5 \\
\hline 5,63 & 5,71 & 5,31 \\
\hline
\end{tabular}




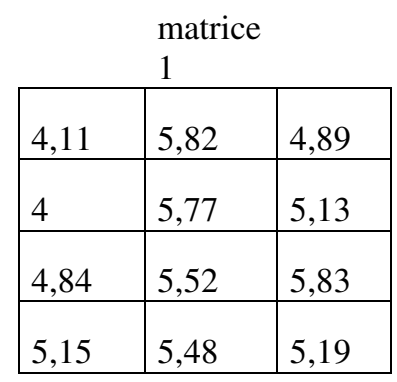

\begin{tabular}{|c|c|c|}
\hline 4,15 & 3,98 & 5,01 \\
\hline 5,7 & 4,83 & 5,37 \\
\hline 4,96 & 4,78 & 4,27 \\
\hline 5,89 & 4,92 & 4,01 \\
\hline
\end{tabular}

matrice
\begin{tabular}{|l|l|l|}
\hline 5,72 & 4,26 & 4,16 \\
\hline 4,12 & 5,15 & 4,18 \\
\hline 5,12 & 4,32 & 4,16 \\
\hline 4,04 & 5,64 & 5,83 \\
\hline
\end{tabular}

\begin{tabular}{|c|c|c|}
\hline 4,68 & 4,94 & 5,34 \\
\hline 6,38 & 4,65 & 4,86 \\
\hline 4,98 & 5,58 & 6,84 \\
\hline 5,56 & 5,82 & 3,67 \\
\hline
\end{tabular}

matrice
\begin{tabular}{|l|l|l|}
\hline 4,22 & 5,04 & 4,71 \\
\hline 4,77 & 4,2 & 4,48 \\
\hline 5,07 & 4,66 & 5,05 \\
\hline 5,49 & 4,27 & 4,42 \\
\hline
\end{tabular}

\begin{tabular}{|c|c|c|}
\hline 5,18 & 4,76 & 5,39 \\
\hline 5,73 & 6,6 & 4,72 \\
\hline 4,13 & 4,84 & 5,85 \\
\hline 5,11 & 5,03 & 6,48 \\
\hline
\end{tabular}

matrice
\begin{tabular}{|l|l|l|}
\hline 5,32 & 4,77 & 5,45 \\
\hline 5,6 & 5,31 & 5,25 \\
\hline 5,67 & 4,21 & 5,84 \\
\hline 4,74 & 4,67 & 4,7 \\
\hline
\end{tabular}

\begin{tabular}{|c|c|c|}
\hline 5,08 & 6,13 & 3,55 \\
\hline 5,1 & 6,59 & 5,75 \\
\hline 3,43 & 4,69 & 4,86 \\
\hline 5,86 & 6,13 & 4,8 \\
\hline
\end{tabular}

matrice
\begin{tabular}{|l|l|l|}
\hline 5,79 & 5,55 & 4,43 \\
\hline 5,14 & 5,91 & 4,12 \\
\hline 5,95 & 5,42 & 4,36 \\
\hline 4,69 & 4,04 & 4,37 \\
\hline
\end{tabular}

matrice
\begin{tabular}{|l|l|l|}
\hline 3,91 & 4,25 & 6,47 \\
\hline 5,66 & 4,39 & 6,28 \\
\hline 3,95 & 5,08 & 5,63 \\
\hline 4,81 & 5,06 & 5,91 \\
\hline
\end{tabular}




matrice
\begin{tabular}{|l|l|l|}
\hline 5,41 & 4,71 & 5,88 \\
\hline 5,16 & 5,87 & 4,44 \\
\hline 5,64 & 5,17 & 5,19 \\
\hline 4,38 & 4,33 & 4,62 \\
\hline
\end{tabular}

\begin{tabular}{|c|c|c|}
\hline 3,69 & 5,69 & 5,02 \\
\hline 4,83 & 4,63 & 5,86 \\
\hline 5,26 & 5,79 & 5,81 \\
\hline 6,32 & 4,67 & 5,58 \\
\hline
\end{tabular}

\begin{tabular}{|c|c|c|}
\hline \multicolumn{3}{|c|}{$\begin{array}{l}\text { matrice } \\
1\end{array}$} \\
\hline 5,55 & 4,92 & 4,39 \\
\hline 5,32 & 4,43 & 4,81 \\
\hline 4,53 & 5,43 & 4,17 \\
\hline 4,61 & 4,31 & 5,23 \\
\hline
\end{tabular}

\begin{tabular}{|c|c|c|}
\hline 3,85 & 6,08 & 4,91 \\
\hline 4,78 & 6,57 & 4,37 \\
\hline 6,27 & 5,17 & 6,43 \\
\hline 5,79 & 5,89 & 5,19 \\
\hline
\end{tabular}

matrice
\begin{tabular}{|l|l|l|}
\hline \multicolumn{1}{|l}{1} & 5,14 & 4,49 \\
\hline 5,96 & 5,95 & 5,56 \\
\hline 5,64 & 5,17 & 5,17 \\
\hline 4,63 & 4,17 & 4,21 \\
\hline
\end{tabular}

matrice
\begin{tabular}{|l|l|l|}
\hline 5,44 & 3,96 & 4,81 \\
\hline 4,54 & 4,04 & 4,74 \\
\hline 3,56 & 4,63 & 4,23 \\
\hline 5,47 & 6,33 & 4,79 \\
\hline
\end{tabular}

\begin{tabular}{|c|c|c|}
\hline 4,91 & 4,73 & 4,23 \\
\hline 5,97 & 5,5 & 5,98 \\
\hline 5,89 & 5,4 & 4,97 \\
\hline 5,19 & 5,39 & 5,16 \\
\hline
\end{tabular}

\begin{tabular}{|c|c|c|}
\hline 4,29 & 4,5 & 4,97 \\
\hline 4,63 & 4,57 & 3,92 \\
\hline 5,01 & 5,1 & 5,23 \\
\hline 5,01 & 3,71 & 5,14 \\
\hline
\end{tabular}

\begin{tabular}{|c|c|c|}
\hline 5,08 & 4,74 & 5,52 \\
\hline 4,29 & 4,39 & 5,04 \\
\hline 4,85 & 4,32 & 4,38 \\
\hline 4,6 & 4,92 & 5,9 \\
\hline
\end{tabular}

\begin{tabular}{|l|l|l|}
\multicolumn{2}{c}{ matrice } \\
\multicolumn{1}{|c|}{2} \\
\hline 4,42 & 5,06 & 4,96 \\
\hline 5,51 & 4,91 & 4,68 \\
\hline 4,65 & 5,88 & 4,62 \\
\hline 5,2 & 5,58 & 4,4 \\
\hline
\end{tabular}




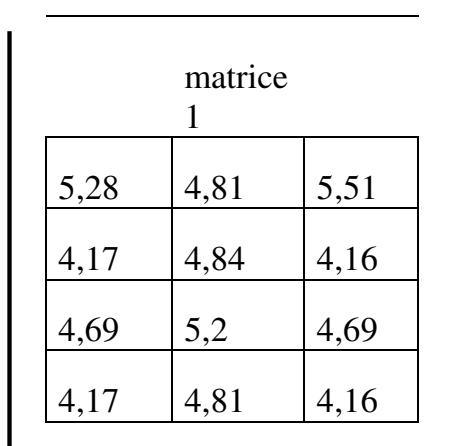

\begin{tabular}{|c|c|c|}
\hline \multicolumn{3}{|c|}{$\begin{array}{l}\text { matrice } \\
2\end{array}$} \\
\hline 5,12 & 5,16 & 3,79 \\
\hline 5,43 & 5,17 & 5,74 \\
\hline 5,11 & 5 & 5,01 \\
\hline 5,43 & 5,69 & 5,74 \\
\hline
\end{tabular}

\begin{tabular}{|c|c|c|}
\hline \multicolumn{3}{|c|}{$\begin{array}{l}\text { matrice } \\
1\end{array}$} \\
\hline 5,99 & 5,88 & 5,74 \\
\hline 5,19 & 5,05 & 5 \\
\hline 4,39 & 5,84 & 5,22 \\
\hline 5,53 & 5,87 & 5,75 \\
\hline
\end{tabular}

\begin{tabular}{|c|c|c|}
\hline 3,01 & 3,42 & 4,06 \\
\hline 4,51 & 4,26 & 5,5 \\
\hline 5,11 & 4,95 & 5,78 \\
\hline 5,07 & 3,23 & 3,45 \\
\hline
\end{tabular}

matrice
\begin{tabular}{|l|l|l|}
\hline 5,11 & 5,97 & 4,36 \\
\hline 5,6 & 4,84 & 4,37 \\
\hline 5,26 & 4,61 & 5,98 \\
\hline 4,71 & 5,46 & 5,02 \\
\hline
\end{tabular}

\begin{tabular}{|c|c|c|}
\hline & \multicolumn{2}{|c|}{$\begin{array}{l}\text { matrice } \\
2\end{array}$} \\
\hline 4,09 & 3,33 & 5,44 \\
\hline 5,08 & 6,06 & 6,03 \\
\hline 4,84 & 4,49 & 4,82 \\
\hline 6,19 & 4,74 & 4,4 \\
\hline
\end{tabular}

matrice
1
\begin{tabular}{|l|l|l|}
\hline 4,88 & 5,96 & 4,8 \\
\hline 5,75 & 4,85 & 5,78 \\
\hline 4,57 & 4,39 & 4,87 \\
\hline 4,51 & 5,18 & 4,71 \\
\hline
\end{tabular}

matrice
\begin{tabular}{|l|l|l|}
\hline 4,92 & 4,94 & 4,3 \\
\hline 3,55 & 4,65 & 4,82 \\
\hline 5,39 & 5,01 & 5,23 \\
\hline 5,43 & 4,22 & 5,79 \\
\hline
\end{tabular}

matrice
1
\begin{tabular}{|l|l|l|}
\hline 4,22 & 4,74 & 5,04 \\
\hline 4,29 & 4,39 & 5,52 \\
\hline 4,85 & 4,32 & 5,9 \\
\hline 4,6 & 4,92 & 4,38 \\
\hline
\end{tabular}

matrice
\begin{tabular}{|l|l|l|}
\hline 4,42 & 5,06 & 4,97 \\
\hline 5,51 & 4,91 & 4,68 \\
\hline 4,65 & 5,88 & 5,62 \\
\hline 5,2 & 5,77 & 4,4 \\
\hline
\end{tabular}

